\title{
Manuel Lavaniegos Espejo. Los saberes de la modernidad. Aproximaciones desde el arte 2. México, Universidad Nacional Autónoma de México, 2019.
}

\author{
Iván Genaro Calzada \\ Universidad Nacional Autónoma de México \\ gencalito@gmail.com \\ orcid.org/oooo-ooo3-4417-4734
}

En este libro, Manuel Lavaniegos toma como punto de partida la obra de Wassily Kandinsky para reflexionar sobre el surgimiento del arte abstracto. Más allá de dar una interpretación de las obras del artista ruso, ofrece una guía para entender cuál fue el proceso que siguió el pintor para concebirlas; a forma de recorrido, encamina al lector por cinco pinturas que ejemplifican el desarrollo y maduración de la técnica del pintor para llegar a un producto final: descubrir el punto cumbre de su abstracción.

Una de las aportaciones más importantes que plantea Lavaniegos es que el arte abstracto no es una nueva ejecución artística, sino un replanteamiento, producto de la modernidad, de los valores artísticos que se han manifestado desde los tiempos prehistóricos del arte; es una corriente que rompe con la hasta entonces aceptada idea de lo que debía ser pintado, según los modelos de épocas como el Renacimiento.

El arte abstracto rescata la subjetividad de nuestra realidad; no pretende te- ner como único objetivo el lienzo, sino toda una visión que despierte y recorra los sentidos; se esfuerza por transmitir la emoción que estaba en la mente del autor, pasarla al lienzo en forma de imagen y finalmente llegar a un espectador para que este sienta el choque emocional que provoca la creación de una pintura.

Manuel Lavaniegos analiza cinco creaciones de Kandinsky: Primera acuarela abstracta (1910), Lírico (1911), Composición II (1909-1910), Composición VII (1913) y Algunos círculos (1926); se apoya en algunos escritos del artista, entre ellos: $\mathrm{Mi}$ rada retrospectiva, De lo espiritual en el arte, La gramática de la creación. El futuro de la pintura y Punto y línea sobre el plano. Contribución al análisis de los elementos pictóricos, que en conjunto representan la gestación crítica, teórica y práctica del autor.

Trataré de presentar aquí de una manera sencilla su trabajo:

Lavaniegos inicia con Primera acuarela abstracta; la describe como "el surgimiento de los remolinos gráficos y cro- 
máticos" (28), el mismo Kandinsky se expresa de esta como "la estación del 'grado cero' de complejísimas búsquedas abstracto/espirituales" (32); esto significa que la obra de arte es la exteriorización de la interioridad del artista; es un conjunto de expresiones artísticas que apelan a los sentidos a través de colores, sensaciones, tonalidades, texturas, etcétera.

Lírico, para Lavaniegos, es un cuadro todavía figural con un bajo grado de abstracción; aún se puede apreciar un objeto principal frente al lienzo: un jinete cabalgando, posiblemente evitando un obstáculo; la importancia del cuadro radica primordialmente en que dicha figura da "la sensación [al espectador] de 'ir a caballo', de incorporarnos en la fluidez emocional contenida en la alegría de su dinamismo plástico" (42); el pintor juega con las sensaciones que quiere transmitir al receptor, que pueda sentir la velocidad, el ruido de los cascos del caballo al tocar el suelo, las ramas que esquivan ambos y que aprecie el entorno libre donde surca el cielo y sopla el viento sin tensión. En esta obra Lavaniegos rescata "la unidad del arte y la naturaleza" (44), porque en la pintura de Kandinsky encontramos el origen del mundo, expresado en el choque de técnicas, colores, concepciones, instrumentos, y al mismo tiempo el fin del mundo, expresado en el resultado último del cuadro: el origen de una pintura es el choque de mundos, el fin de uno y el comienzo de otro.

Composición II, señala el autor, tiene un mayor nivel de abstracción que el anterior; no obstante, aún se aprecian "el paisaje y los seres que lo surcan, presos de una convulsa agitación, esquematizados por marcados contornos" (54); en este cuadro de tonos amarillentos, conviven sin distinción de relevancia "colinas, árboles y montículos, hasta las nubes y la dentada luz solar han adquirido, cada uno por su parte, una suerte de alma propia, atraídos y, simultáneamente, expelidos por el fuerte abismo que parece hundir toda la composición hacia su centro" (54-55).

Aquí, Lavaniegos nos ofrece una explicación del mismo Kandinsky acerca de las concepciones que tenía el pintor para diferenciar sus cuadros como Impresiones, Improvisaciones y Composiciones; entendiendo que las obras pueden estructurarse en simples o complejas, tal como sucede con las melodías: las Impresiones, como su nombre refiere, son la "impresión directa de la naturaleza externa” (56); las Improvisaciones son "la impresión de la naturaleza interna” (56), una expresión inconsciente; en tanto que las Composiciones son la "expresión que se crea con lentitud extraordinaria que analizo y trabajo larga y pedantemente después del primer esbozo" (56), estas últimas son, por su grado de complejidad, señala Lavaniegos, el trabajo más laborioso, pero también más fructífero, ya que, de estas obras se pueden obtener distintas interpretaciones de acuerdo a su etapa de elaboración.

Composición VII, refiere el autor, es considerado uno de los peldaños más altos de la abstracción alcanzados por Kandinsky, donde el estilo da como resultado una "sucesión de catástrofes que desembocan en un cosmos pictórico" (64), dice 
el crítico de arte Jorge Juanes. Observando esta pintura se puede apreciar la complejidad de las formas en las que no siempre es posible reconocer el inicio, el fin y los límites de estas. Contiene en su interior un movimiento envolvente que plasma la explosión del origen del mundo. Aunque ya no hay un objeto principal o en primer plano, se puede decir que esto no es lo primero que tendría que ver el espectador, sino la fuerza de los trazos, que le permitan sumergirse en el interior del torbellino y participar de todas las formas posibles que incita el cuadro.

Algunos círculos es una pintura bastante tardía comparada con las anteriores, desarrolladas entre 1909 y 1913; esta data de 1926, época en que Kandinsky ya había alcanzado un grado de abstracción impresionante. Para Lavaniegos, este cuadro muestra una peculiar complejidad; si bien no está "lleno" de formas, como los anteriores, guarda su propia profundidad y estilo; "utiliza con audacia las formas geométricas regulares y arquetípicas" (70); el círculo es el punto de partida capaz de convertirse en cualquier otra figura: en el fondo, enfrente y en lo lejano hay círculos, que, por su tonalidad y tamaño, cada uno transmite un mensaje diferente; ¿cuál es ese mensaje?, le toca al espectador interpretarlo; hay quienes afirman que el círculo principal, de color negro, es la "ausencia de vida", en tanto que el cuadro en conjunto es silencio a la vez que sonoridad, valdría decir que las interpretaciones son pertinentes en tanto que el espectador lo sienta y la única forma de hacerlo es volverse partícipe de la obra con sus cinco sentidos.
Concluimos con que existe la idea errónea de que el arte abstracto es aquel que carece de formas específicas y por lo tanto es "difícil" de entender. Kandinsky en sus escritos formuló toda una teoría que se ha convertido en un eje principal para la construcción del arte contemporáneo: comprender la abstracción del arte es más complicado que entender la ciencia, afirma Sigfried Giedion (13), no solo por la forma en que la información/mensaje es trasmitido, sino porque también interviene la interpretación del receptor y los procesos mentales que en esta participan. La abstracción es una forma de simbolizar el conocimiento humano y es una capacidad que solo nosotros poseemos; la transformación de una idea en una figura funciona de la misma manera en que interpretamos el mundo, el arte nunca es un reflejo de la realidad; es solo una representación de esta. Simbolizamos el mundo todo el tiempo, y todo aquello que nos rodea posee un grado de abstracción; al mismo tiempo que "vemos la realidad" también imaginamos dentro de nuestra propia realidad; por ello abstraemos ideas que si expresáramos en forma de arte se convertirían en imágenes no figurativas.

\section{Iván Genaro Calzada}

Estudiante de la Licenciatura en Lengua y Literaturas Hispánicas en la Facultad de Filosofía y Letras de la Universidad Nacional Autónoma de México. Realiza su servicio social en Interpretatio. Revista de Hermenéutica, en el IIFL de la UNAM. 